\title{
Influence of Change of Si/AI Ratio on the Synthesis of Mesoporous Aluminosilicates and Flexural Strength of Novolac Composites
}

\author{
Beata Strzemiecka $^{1} \cdot$ Mariusz Sandomierski $^{1}$ (iD $\cdot$ Adam Voelkel $^{1}$
}

Received: 24 September 2018 / Accepted: 9 January 2019 / Published online: 23 January 2019

(c) The Author(s) 2019, corrected publication 2019

\begin{abstract}
Fillers used in phenol-formaldehyde resins should have high thermal stability, be cheap and do not have a negative impact on the resin crosslinking process. These features have mesoporous aluminosilicates which are used in many industries. In this work, effective and simple synthesis of mesoporous materials (with a different Si/Al ratio) from a solid source of silicon has been presented. Materials were used as fillers for phenol-formaldehyde composites. Synthesized mesoporous aluminosilicates have been characterized using Scanning electron microscopy, Energy dispersive spectrometry, Transmission electron microscopy, X-ray Difractometry, Nitrogen adsorption/desorption measurements and Inverse gas chromatography. The properties of the obtained materials are closely related to the amount of aluminum and silicon in the tested materials. All synthesized materials have a larger specific surface area than the substrates used during the synthesis. The mechanical properties of the novolac composites were tested using three-point flexural test. The composite with aluminosilicate which have the lower surface area has the highest flexural strength and it is higher than the strength of the composites with substrates.
\end{abstract}

Keywords Composites $\cdot$ Mesoporosus $\cdot$ Aluminosilicates $\cdot$ Phenol-formaldehyde resins

\section{Introduction}

One of the most commonly used types of organic binders in abrasive tools are phenol-formaldehyde resins [1]. Phenol-formaldehyde resins represent $2 \%$ of the world's polymer production. They are divided into novolacs which are synthesized using an excess of phenol to formaldehyde under acidic conditions and resoles which are obtained using an excess of formaldehyde to the phenol under basic conditions [2]. Resole is cured by heat, acids and bases while novolac is cured using cross-linking agent (urotropine) [3]. Their wide application in abrasive tools is associated with high hardness, thermal stability, chemical resistance and their ability to cure by heating which facilitates production processes $[3,4]$. The main elements of abrasive tools are abrasive particles, wetting agent, binder and filler $[5,6]$. The last component should have high thermal stability, be cheap

Mariusz Sandomierski

mariuszsandomierski@wp.pl

1 Institute of Chemical Technology and Engineering, Poznań University of Technology, Berdychowo 4, 60-965 Poznań, Poland and do not have a negative impact on the resin crosslinking process.

These features have mesoporous aluminosilicates which are used in many industries (e.g. adsorption processes, catalysis) due to their unique properties but they were not used as fillers in phenol-formaldehyde resins yet [7, 8]. Despite the current lack of reports on the use of mesoporous aluminosilicates in this type of resins, aluminosilicate-polymer composites have already been used in environmental sensors, biosensors, drug delivery, tissue engineering [9-12]. The materials characterized by very high thermal stability are the MSU type mesoporous materials. The abbreviation MSU refers to mesoporous silica, mesoporous alumina and mesoporous aluminosilicates [13-15]. MSU materials change their properties along with changing the aluminum content in their structure. Bagshaw and co-authors obtained MSU materials in which increase of aluminium content leads to the decrease of the pore size and catalytic activity but better hexagonal pore ordering [16-18]. The addition of the higher amount of aluminium during aluminosilicate synthesis has an effect on the change in the amount of type of bonds ( $\mathrm{Si}-\mathrm{O}-\mathrm{Si}$; $\mathrm{Si}-\mathrm{O}-\mathrm{Al}$; $\mathrm{Al}-\mathrm{O}-\mathrm{Al})$ in the analyzed material. These bonds have different angles which affects the formation of various structures. Despite many studies on 
mesoporous materials there are few reports on their preparation from a solid silicon source. Synthesis should be simple and possible to be made on a large scale. Solid silicon sources provide more silicon to the reaction environment than the most commonly used sodium silicates. The new direction of the synthesis of mesoporous materials is their preparation from less toxic and less expensive substrates [19]. Materials obtained in this way have a chance to be used as fillers in phenol formaldehyde resins.

The aim of this work was to propose a simple synthesis of the mesoporous aluminosilicates. Raw materials were solid silicon and solid aluminum sources with low toxicity and price (in comparison to popularly used substrates). It was assumed that the obtained aluminosilicates with different $\mathrm{Si} / \mathrm{Al}$ ratio will be used for the first time as the potential fillers for the phenol-formaldehyde composites. Therefore, synthesized mesoporous aluminosilicate materials have been extensively characterized. Special attention was paid to check the influence of the amount of aluminum on the both physicochemical and mechanical properties of composites.

\section{Materials Synthesis}

Five types of aluminosilicate fillers were obtained using the same procedure but a different ratio of substrates. Fillers were prepared according to the following procedure: sodium hydroxide (Sigma-Aldrich, 97\%) and sodium aluminate (Avantor, $~ 99 \%$ ) were dissolved in the distilled water [20]. Then, a silicon dioxide (Sigma-Aldrich, 99\%) was added to $\mathrm{NaOH}$ solution. Next, both mixtures were mixed and stirred at room temperature for $1 \mathrm{~h}$ and then were heated and mechanically stirred at $100{ }^{\circ} \mathrm{C}$ for $24 \mathrm{~h}$.

The obtained mixture was mixed with solution of cetyltrimethylammonium bromide (BioXtra, 99\%) in distilled water. After $1 \mathrm{~h}$ stirring sulfuric acid (Avantor, 95\%) was added to obtain $\mathrm{pH} 9-10$ and then mixture was stirred for $24 \mathrm{~h}$. The samples were crystallized for $48 \mathrm{~h}$ at $100{ }^{\circ} \mathrm{C}$ under static conditions. The resulting fillers were filtered, washed with distilled water and dried at room temperature. The last step was removal of the template by calcination at $540{ }^{\circ} \mathrm{C}$ for $7 \mathrm{~h}$. The theoretical $\mathrm{Si} / \mathrm{Al}$ weight ratio of the examined fillers are presented in the Table 1.

\subsection{Scanning Electron Microscopy (SEM)/Energy Dispersive Spectrometry (EDS)}

SEM images were recorded using FEI Quanta FEG with field emission electron source under high vacuum mode, with accelerating voltage at $18 \mathrm{kV}$. The SEM toll is equipped with EDS analyzer made by EDAX.

\subsection{Transmission Electron Microscopy (TEM) Observation}

The tested material was scattered into copper mesh coated with carbon film and analyzed in Transmission Electron Microscope (TEM) Hitachi HT7700 (at $100 \mathrm{kV}$ of accelerating voltage).

\subsection{Fourier-Transform Infrared Spectroscopy (FTIR)}

FTIR analysis was carried out using Vertex70 spectrometer, Bruker Optics. All materials were studied by using single reflection, diamond ATR crystal. The tests were performed at a resolution of $0.5 \mathrm{~cm}^{-1}$ in the wavenumber range $4000-600 \mathrm{~cm}^{-1}$.

\subsection{Nitrogen Adsorption/Desorption Measurements}

The specific surface area, pore volume and average pore size were determined on the basis of low-temperature nitrogen adsorption/desorption isotherms. Measurement was carried out using a conventional volumetric technique on a ASAP 2420 sorptometer (Micromeritics). The measurements were carried out at the boiling point of nitrogen $\left(-196^{\circ} \mathrm{C}\right)$. Before experiments the samples were outgassed at $200{ }^{\circ} \mathrm{C}$ in a vacuum chamber.

In order to determine the specific surface, the theory proposed by Brunauer, Emmett and Teller was used. The amount of adsorbed gas (pairs of nitrogen) $\boldsymbol{n}$, measured in equilibrium with the pressure $p$ of the adsorbed gas, was plotted against the relative pressure $p / p^{\circ}$, thus obtaining the adsorption isotherm. The adsorptive capacity of the monolayer $\boldsymbol{n}_{m}$, necessary to determine the specific surface of the material, was obtained using the linear form of the BET equation [21].

$$
\frac{p / p^{\circ}}{\boldsymbol{n}\left(1-\frac{p}{p^{\circ}}\right)}=\frac{1}{\boldsymbol{n}_{m} C}+\frac{C-1}{\boldsymbol{n}_{m} C}\left(\frac{p}{p^{\circ}}\right)
$$

Table 1 Temperature program used during annealing of composites

\begin{tabular}{lllllllllll}
\hline $\mathrm{h}$ & 1 & 1 & 3 & 5 & 1 & 2 & 2 & 1 & 4 & 10 \\
\hline${ }^{\circ} \mathrm{C}$ & to 50 & in 50 & to 80 & in 80 & to 115 & in 115 & to 140 & in 140 & to 180 & in 180 \\
\hline
\end{tabular}


where $\boldsymbol{n}$ is the specific amount adsorbed at the relative pressure $p / p^{\circ}$ and $\boldsymbol{n}_{m}$ is the specific monolayer capacity while $\mathrm{C}$ is constant value.

The second step is the calculation of the BET-area from the monolayer capacity.

$\alpha_{s}(B E T)=\boldsymbol{n}_{m} \times L \times \sigma_{m} / m$

where $\sigma_{m}$ is molecular cross-sectional area, $m$ is mass and $\alpha_{s}(\mathrm{BET})$ is the BET surface area of the material.

The function of pore volume distribution was calculated based on the adsorptive isotherm branch using BarrettJoyner-Halendy (BJH) method. Choosing the desorption part of the isotherm would cause others location and shape of the distribution curve. This is because the desorption branch is affected by the effects of blocking the pores which contribute to shifting the curve toward smaller pores [22].

\subsection{X-ray Difractometry (XRD)}

The powders were examined by the X-ray diffraction method in the range of $2 \theta$ from 2 to 70 using a Bruker D8 Advance difractometer with Johanson monochromator and LynxEye detector. Measurement step was between 0.002 and 0.03 depending on the sample size, while the time for each step was between 2 and $3 \mathrm{~s}$. Samples were measured in polymethyl methacrylate cuvette. $\lambda \mathrm{Cu} \mathrm{K}_{\alpha 1}=1,5406 \AA$.

\subsubsection{Scherrer Crystallite Size}

Crystallite size was calculated using Scherrer equation. The relationship, which was first published by Scherrer can be given as:

$d=\frac{K \lambda}{\beta \cos \theta}$

where: $d=$ crystallite size, which may be smaller or equal to the grain size; $K=$ the shape constant; $\lambda=$ the wavelength of the X-ray source applied; $\beta=$ the reflection width; $\theta=$ the Bragg angle [23, 24].

\subsection{Inverse Gas Chromatography}

The surface properties of the fillers were characterized by means of inverse gas chromatography. The measurements were performed using Surface Energy Analyzer produced by SMS Ltd., London. The materials under test were placed into the chromatographic columns (silanized glass columns, I.D. $4 \mathrm{~mm}$, length $30 \mathrm{~cm}$ ) by the tap-and-fill method. The measurements were carried out at $30{ }^{\circ} \mathrm{C}$. The temperature of injector as well as FID detector was $180^{\circ} \mathrm{C}$. Helium was a carrier gas with flow rate $15 \mathrm{ml} / \mathrm{min}$.

Dispersive component of the free surface energy, $\gamma_{s}^{d}$, that express dispersive properties of the surface was estimated according to Schultz-Lavielle procedure using n-alkanes as test compounds (hexane, heptane, octane, nonane, decane) $[25,26]$.

\subsection{Composite Preparation}

Fillers (25\%) and novolac resin (75\%) (Lerg) were mechanically mixed and placed in a mold and then annealed in oven (Table 1.). The dimension of composites after annealing was equal to $50 \times 10 \times 4 \mathrm{~mm}$.

\subsection{Flexural Strength of Composites}

Three-point flexural test was conducted using a Zwick Z010 TN ProLine testing machine according to PN-EN ISO 178 standard.

\section{Results}

The results obtained by the EDS analysis confirm the theoretical $\mathrm{Si} / \mathrm{Al}$ ratios. This proves the efficiency of synthesis despite its simplicity and lack of substrate loss during individual steps.

Along with the increase in the aluminum content in the materials, the content of sodium also increases. It results from the structure of aluminosilicates, the main element of this structure are TO4/2 tetrahedra, where $\mathrm{T}$ is silica or aluminum. The silica incorporated in the aluminosilicate structure is tetravalent whereas the aluminum is trivalent therefore silica tetrahedra is electro-neutral while aluminum tetrahedral is negatively charged. The charge of the entire network is equivalent due to the presence of metal (sodium) in its structure [27] (Table 2).

The size of aluminosilicate agglomerates increases with declines of $\mathrm{Si} / \mathrm{Al}$ ratio (Fig. 1). Fillers containing a high silicon content have a more irregular structure. Fillers with a high aluminum content form large planar particles.

The AS1 material has a structure typical for ordered mesoporous aluminosilicates (Fig. 2, marked with arrows).

Table $2 \mathrm{Si} / \mathrm{Al}$ weight ratio and sodium content of the examined fillers determined by SEM / EDS

\begin{tabular}{lcrr}
\hline Type of filler & \multicolumn{2}{c}{ Si/Al ratio } & Sodium content \\
\cline { 2 - 3 } & Theoretical & \multicolumn{2}{c}{$\begin{array}{l}\text { Determined by } \\
\text { SEM/EDS }\end{array}$} \\
\hline AS1 & 12.76 & $13.16 \pm 1.16$ & $2.22 \pm 0.21$ \\
AS2 & 2.63 & $2.61 \pm 0.22$ & $8.14 \pm 0.64$ \\
AS3 & 1.42 & $1.54 \pm 0.11$ & $9.88 \pm 0.73$ \\
AS4 & 0.76 & $0.71 \pm 0.16$ & $17.15 \pm 1.17$ \\
AS5 & 0.16 & $0.1 \pm 0.15$ & $17.52 \pm 1.18$ \\
\hline
\end{tabular}




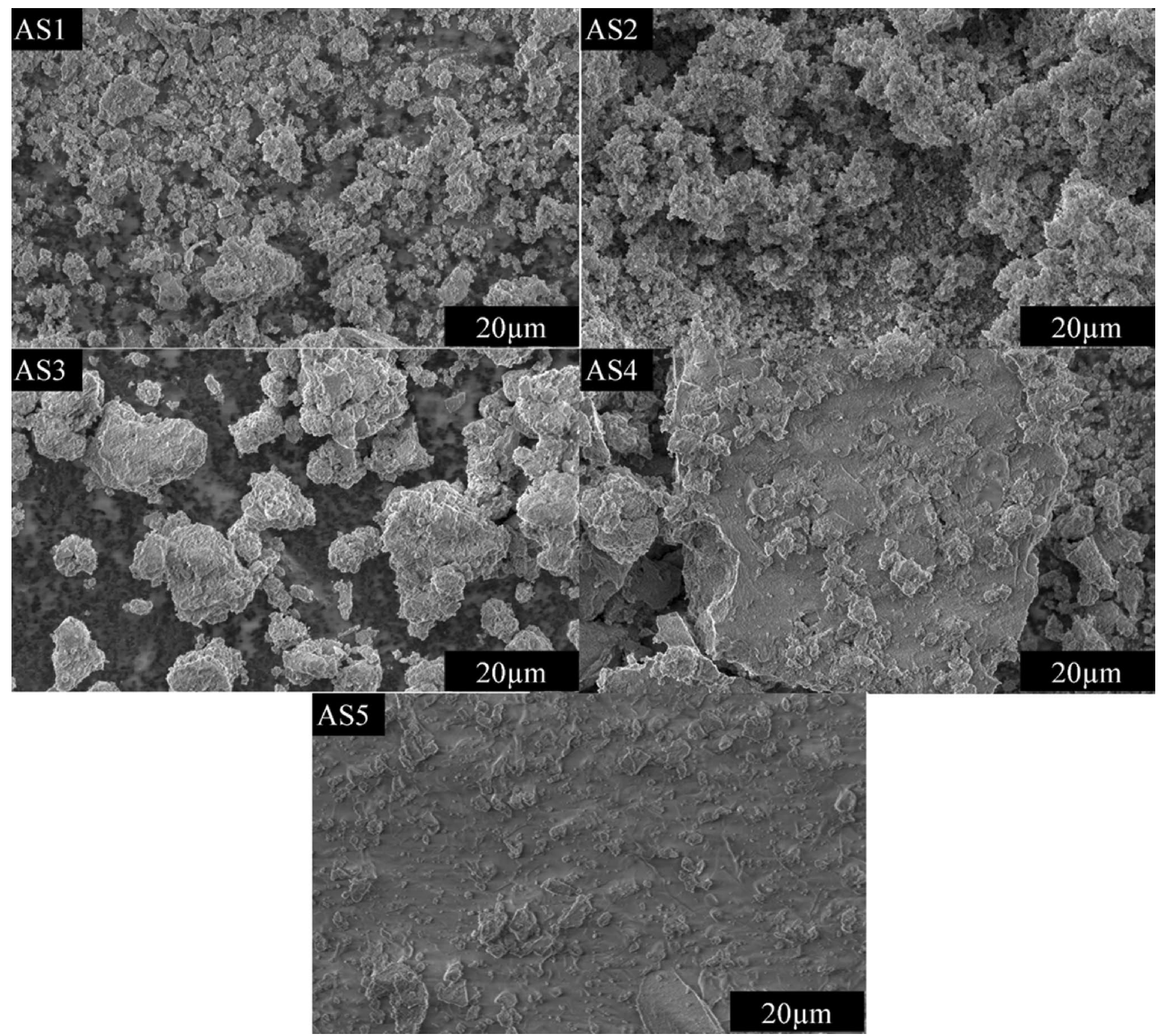

Fig. 1 SEM images of examined fillers

In the image of the analyzed samples mesopores are visible. For other materials, no ordered structure was observed. In the TEM photographs of AS2 and AS3 aluminosilicate longitudinal structures are visible which are similar to those assigned to the ZSM-5 aluminosilicate type materials [28]. Structures similar to those in AS2 and AS3 materials are also found in AS5 material but in this case they are associated with the occurrence of aluminum oxide [29, 30]. Based on the TEM analysis, it is evident that the primary particles have a size $<100 \mathrm{~nm}$ but a thorough analysis is not possible due to the lack of material homogeneity.

The main peaks in the all aluminosilicates are peaks that are attributed to the quartz which already exists in the substrate and they are marked as "o" (Fig. 3). Material with the highest silicon content have six peaks indicating the existence of aluminosilicate structures (“*”) in composition. This materials also have a broad peak between 17 and $20^{\circ}$ which indicates residual of amorphous silica. In this aluminosilicate also occurs characteristic peaks of mesoporous materials visible in the low XRD angle range (Fig. 4). Possessing peaks in the whole range indicates that it belongs to a group of the ordered mesoporous aluminosilicates with crystalline zeolite wall structure [31]. AS2 and AS3 have the same peaks (in range $5-70^{\circ}$ ) as the previous material but in its structure there are new peaks associated with aluminosilicate structures. The AS4 and five materials have less peaks indicating the presence of aluminosilicate, the remaining peaks can be attributed to aluminium oxide. In AS2-AS5 

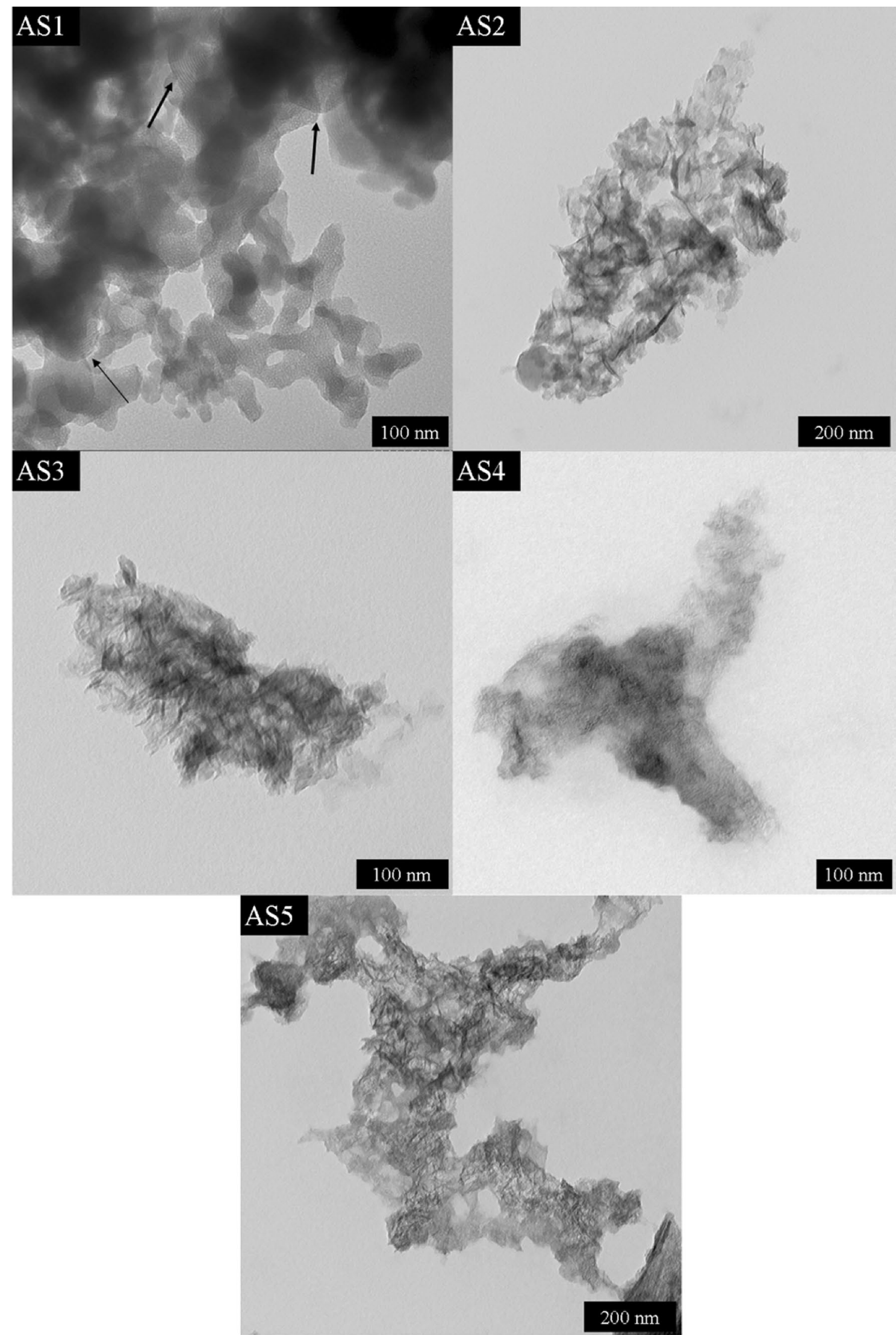

Fig. 2 TEM images of examined fillers 


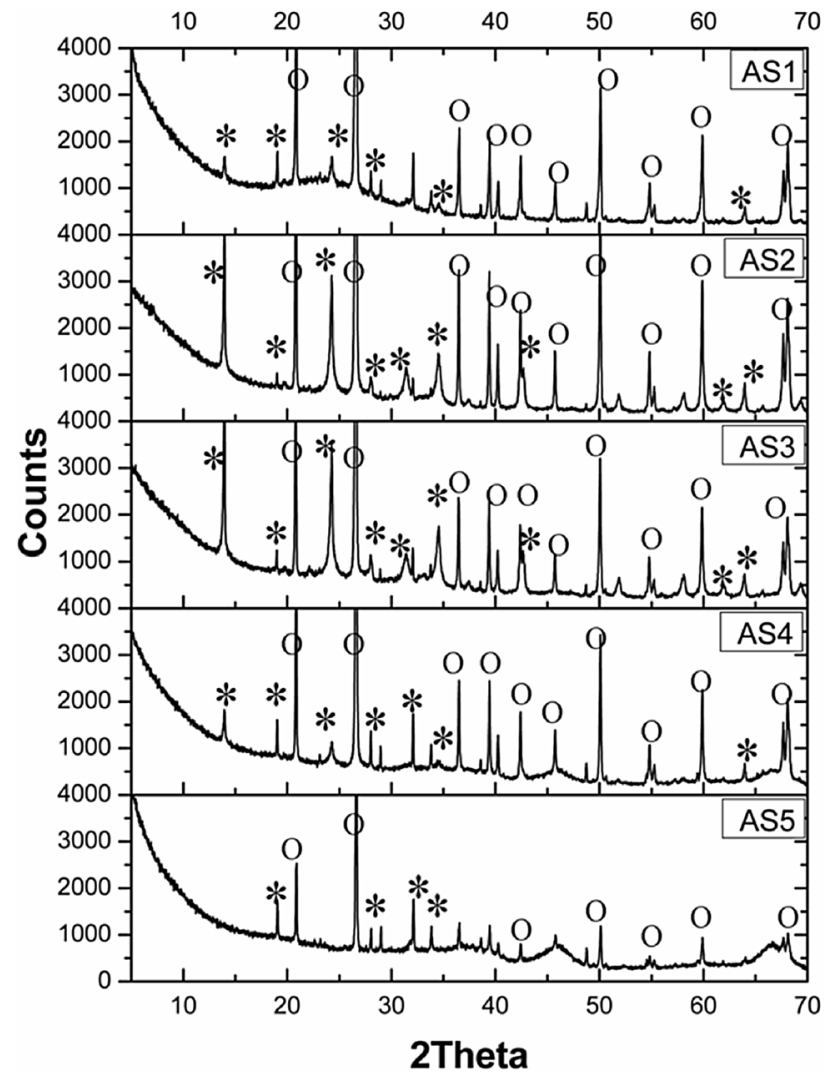

Fig. 3 X-ray diffraction pattern of all obtained aluminosilicates (*-indicate sodium aluminosilicate peaks, o-indicate quartz peaks)

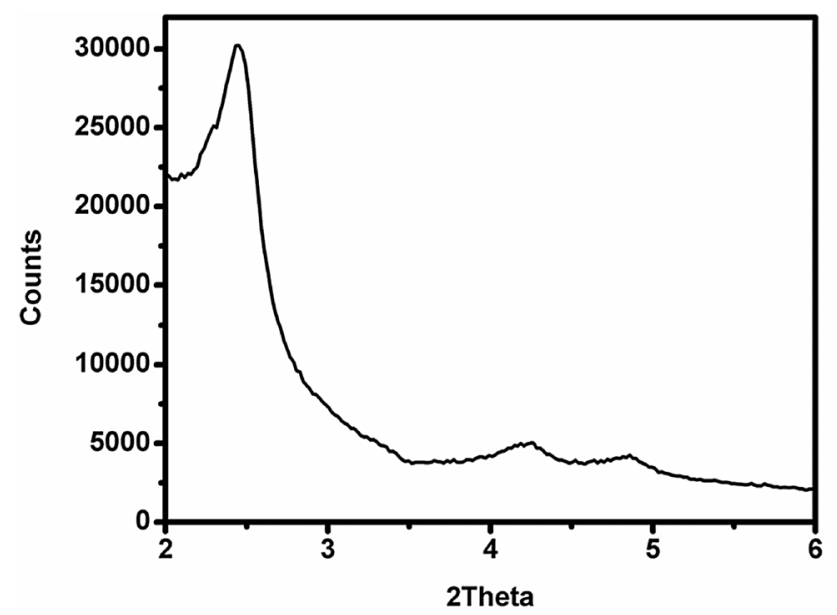

Fig. 4 Low-angle X-ray diffraction pattern of AS1 aluminosilicate

peak between 2 and $5^{\circ}$ do not occur which indicates a low ordering of mesoporous structure [32].

The crystallite size calculated using Scherrer equation based on XRD results in the range between 2 and $70^{\circ}$ is as follows: AS1: $18-84 \mathrm{~nm}, \mathrm{AS} 2: 16-127 \mathrm{~nm}, \mathrm{AS} 3$ : 15-112 nm; AS4: 11-94 nm and AS5: 49-95 nm (these are
Table 3 Textural properties of examined materials

\begin{tabular}{lclc}
\hline Material & $\begin{array}{l}\text { BET surface area } \\
{\left[\mathrm{m}^{2} \mathrm{~g}^{-1}\right]}\end{array}$ & $\begin{array}{l}\text { BJH pore volume } \\
{\left[\mathrm{cm}^{3} \mathrm{~g}^{-1}\right]}\end{array}$ & $\begin{array}{l}\text { BJH average } \\
\text { pore size }[\mathrm{nm}]\end{array}$ \\
\hline SD & 5.51 & 0.02 & 17.8 \\
AS1 & 664.32 & 0.78 & 3.7 \\
AS2 & 275.17 & 0.44 & 4.7 \\
AS3 & 64.27 & 0.24 & 14.3 \\
AS4 & 156.22 & 0.41 & 9.2 \\
AS5 & 272.48 & 0.68 & 8.6 \\
SA & 12.56 & 0.05 & 14.4 \\
\hline
\end{tabular}

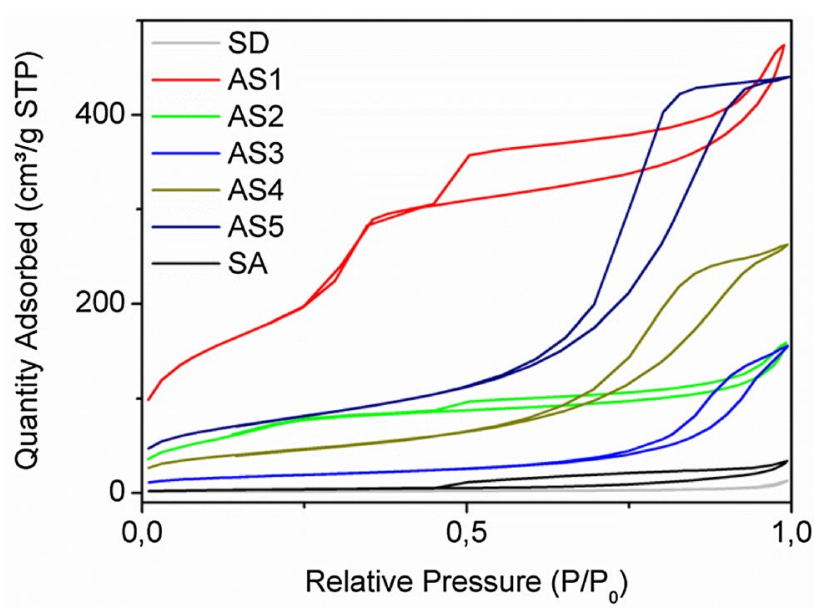

Fig. 5 Adsorption-desorption isotherms of materials

the largest crystallite sizes calculated for individual XRD peaks). The results indicate that the grains with a crystal structure have a maximum $127 \mathrm{~nm}$ size and are present in the AS2 material. Analysis of AS1 ordered material in the range $2-6^{\circ}$ indicates the presence of particles with size up to $14 \mathrm{~nm}, 28 \mathrm{~nm}$ and $13 \mathrm{~nm}$. Calculations for wide peaks $\left(43-38^{\circ}, 64-70^{\circ}\right)$ present only in sample 5 indicate the presence of aluminum oxide with size up to $4 \mathrm{~nm}$. The results obtained using the Scherrer equation are in agreement with the TEM results and also indicate a wide particle size distribution.

The synthesized materials have a larger specific surface area than the substrates used during the synthesis (Table 3). The largest surface area has AS 1 aluminosilicate while the smallest one has AS3 aluminosilicate. The specific surface area of the synthesized materials initially decreases, and then increases in relation to the $\mathrm{Si} / \mathrm{Al}$ ratio. Despite the quartz content (Fig. 3) in the analyzed samples, their specific surface area grows even more than 100 times.

All synthesized materials have a Type IVa isotherm what indicates the mesoporous nature of fillers (Fig. 5). 


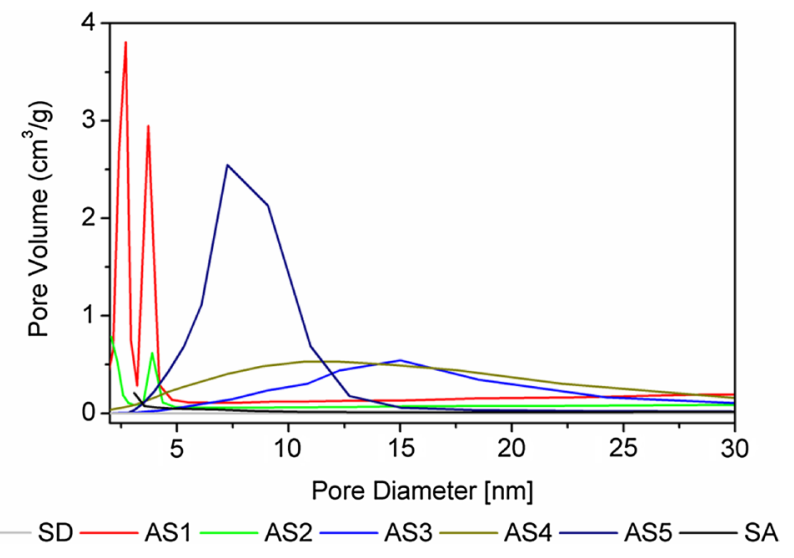

Fig. 6 Pore diameter of examined materials

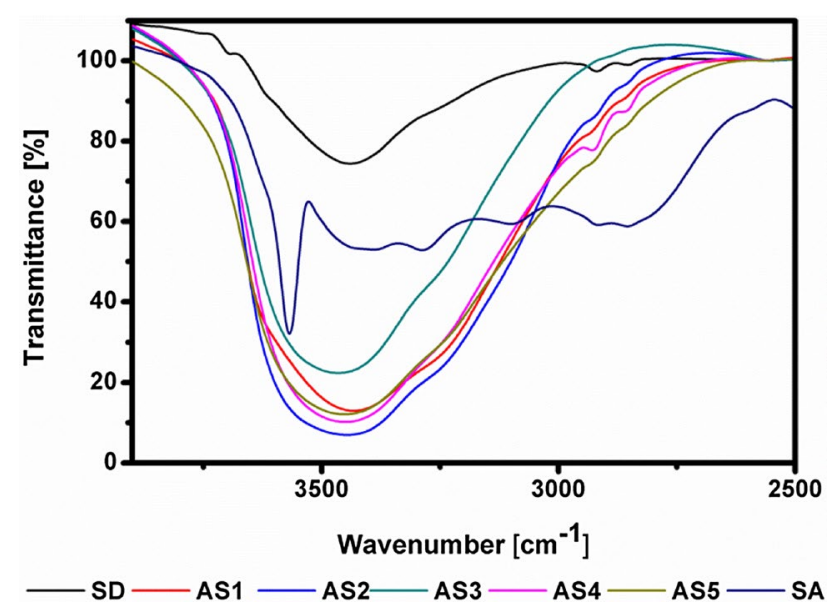

Fig. 7 FTIR spectra of investigated materials at $3800-2500 \mathrm{~cm}^{-1}$ spectral region

Obtained materials have pores in the mesoporous range (Fig. 6). The materials with the highest content of silicon have two characteristic narrow ranges of pore size distribution between 2 and $5 \mathrm{~nm}$. In the case of AS1 material, these pores were also visible in TEM images, despite the presence in the similar range, they were not visible in the AS2 material (Fig. 2). For other materials, the pore size distribution range is larger, which indicates their lack of order and was already visible in the TEM photos.

Analysis of FTIR spectra indicates an increase in the number of hydroxyl groups on the surface of synthesized materials compared to the substrates (Fig. 7). The smallest increase was recorded for material AS3 what is associated with the smallest surface area. The amount of hydroxyl groups on the surface of the material has no effect on the cross-linking of the resin due to the fact that there are only groups linked to silicon or aluminum. During the cross-linking of phenol-formaldehyde resins these groups are linked to a carbon atom which is connected to the aromatic ring.

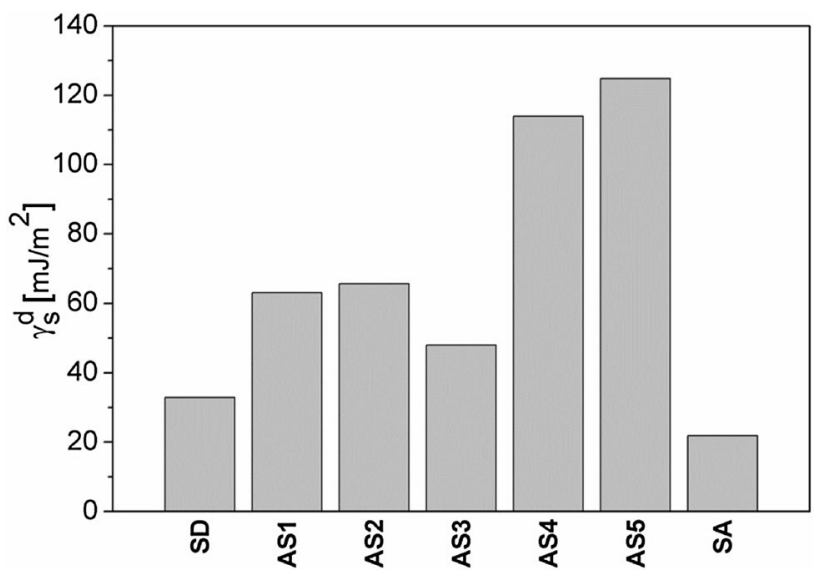

Fig. 8 Dispersive component of the free surface energy

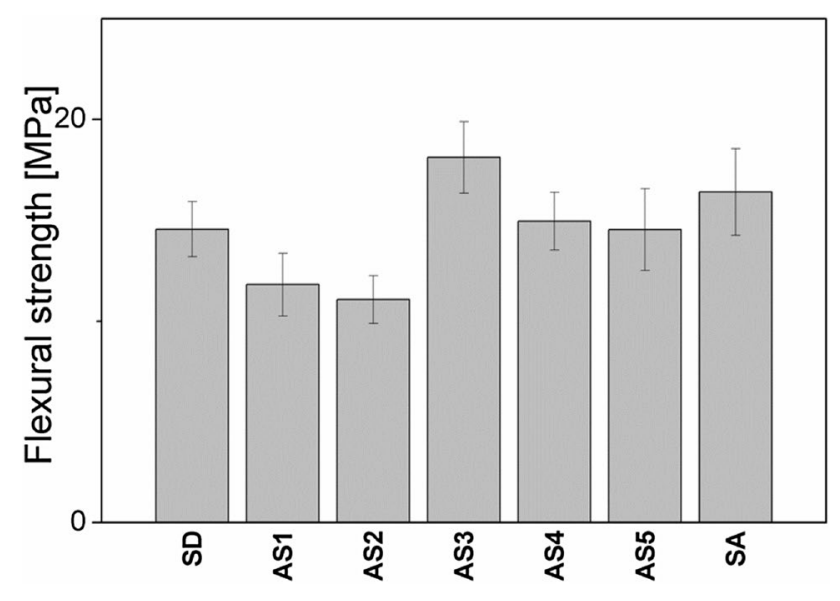

Fig. 9 Flexural strength of composites with examined fillers

Value of the dispersive component of the surface energy of the tested materials increased in comparison to the substrates (Fig. 8) The increase of aluminium content (decrease of $\mathrm{Si} / \mathrm{Al}$ ration) lead to $\gamma_{s}^{d}$ increase and the highest value was found for AS5.

The composite with AS3 filler has the highest flexural strength and it is higher than the strength of the composites with substrates (Fig. 9). In the case of samples AS1 and AS2, the negative effect of a large specific surface area on the strength of the composite is visible. This is due to the fact that the resin does not have the ability to fill the pores, and thus the composite has many empty spaces that have a negative impact on its strength. However, in the case of AS3 material, despite the larger surface area and the pore volume compared to the substrates, higher flexural strength was obtained. 


\section{Conclusion}

The effectiveness of the simple synthesis of mesoporous materials from a solid source of silicon has been presented. The obtained materials had $\mathrm{Si} / \mathrm{Al}$ ratios comparable to those calculated theoretically. During the tests, no linear relationship was observed between the sodium content and the properties of the materials which are closely related to the amount of aluminum and silicon in the tested materials. The particle size of the material agglomerates visibly increases with the increase of the amount of aluminum. Only AS1 material has a structure typical for ordered mesoporous aluminosilicates with visible mesopores. The main peaks in the all materials are peaks that are attributed to the quartz and aluminosilicate structures. For AS1 material also occurs characteristic peaks of mesoporous materials visible in the low XRD angle range. Surface area initially decrease and then increase while dispersive component of the free surface energy increase in relation to the $\mathrm{Si} / \mathrm{Al}$ ratio. The first two materials have pores in a narrow range of $2-5 \mathrm{~nm}$, in the case of two more the range is wide $(2-25 \mathrm{~nm})$ while the AS5 material has pores in the range $(2.5-12.5 \mathrm{~nm})$. The composite material with the highest flexural strength is that with AS3 aluminosilicate having the lowest surface area as well as the smallest amount of hydroxyl groups.

Acknowledgements This work was supported by the National Science Centre. Poland. under research project No. UMO-2015/17/B/ ST8/02388.

Open Access This article is distributed under the terms of the Creative Commons Attribution 4.0 International License (http://creativeco mmons.org/licenses/by/4.0/), which permits unrestricted use, distribution, and reproduction in any medium, provided you give appropriate credit to the original author(s) and the source, provide a link to the Creative Commons license, and indicate if changes were made.

\section{References}

1. L.A. Pilato, Phenolic Resins: A Century of Progress, (SpringerVerlag, Berlin, 2000)

2. V. Ganeshram, M. Achudhan, Indian. J. Sci. Technol. 6, 48144823 (2013)

3. L. Pilato, React. Funct. Polym. 73, 270-277 (2013)

4. K. Hirano, M. Asami, React. Funct. Polym. 73, 256-269 (2013)

5. A. Voelkel, B. Strzemiecka, Int. J. Adhes. Adhes. 27, 188-194 (2007)

6. A. Gardziella, L.A. Pilato, A. Knop, Phenolic Resins Chemistry, Applications, Standarization, Safety and Ecology 2nd edn. (Springer-Verlag, Berlin, 2000)

7. C.-Y. Chen, S.-Q. Xiao, M.E. Davis, Microporous Mater. 4, 1-20 (1995)
8. R. Xu, W. Pang, J. Yu, Q. Huo, J. Chen, Synthesis and structure. Chemistry of zeolites and Related Porous materials, (John Wiley \& Sons, New Jersey, 2007)

9. P. Phumman, S. Niamlang, A. Sirivat, Sensors 9, 8031-8046 (2009)

10. Q. Shi, Q. Li, D. Shan, Q. Fan, H. Xue, Mater. Sci. Eng. C 28, 1372-1375 (2008)

11. S. Sotoudeh, A. Barati, R. Davarnejad, M.A. Farahani, MEJSR 12, 392-396 (2012)

12. D. Rawtani, Y.K. Agrawal, Rev. Adv. Mater. Sci. 30, 282-295 (2012)

13. E. Prouzet, F. Cot, C. Boissière, P.J. Kooyman, A. Larbot, J. Mater. Chem. 12, 1553-1556 (2002)

14. S.A. Bagshaw, T.J. Pinnavaia, Angew. Chem. Int. Edit. Engl. 35, 1102-1105 (1996)

15. K.S. Triantafyllidis, T.J. Pinnavaia, A. Iosifidis, P.J. Pomonis, J. Mater. Chem. 17, 3630-3638 (2007)

16. Y.-M. Luo, Z.-Y. Hou, D.-F. Jin, X.-M. Zheng, Chin. J. Chem. 25(5), 635-639 (2007)

17. S.A. Bagshaw, S. Jaenicke, C.G. Khuan, Ind. Eng. Chem. Res. 42, 3989-4000 (2003)

18. S.A. Bagshaw, S. Jaenicke, C.G. Khuan, Catal. Commun. 4, 140 $146(2003)$

19. Y. Liu, M. Zhao, L. Cheng, J. Yang, L. Liu, J. Wang, Y. Zhang, Microporous Mesoporous Mater. 260, 116-124 (2018)

20. B. Strzemiecka, M. Kasperkowiak, M. Łozynski, D. Paukszta, A. Voelkel, Microporous Mesoporous Mater. 161, 106-114 (2012)

21. M. Thommes, K. Kaneko, A.V. Neimark, J.P. Olivier, F. Rodriguez-Reinoso, J. Rouquerol, K.S.W. Sing, Pure Appl. Chem. 87(9-10), 1051-1069 (2015)

22. J.C. Groen, L.A.A. Peffer, J. Perez-Ramırez, Microporous Mesoporous Mater. 60, 1-17 (2003)

23. J.S.J. Hargreaves, Catal. Struct. React. 2(1-4),33-37

24. I. Alonso-Lemus, Y. Verde-Gómez, L. Álvarez-Contreras, Int. J. Electrochem. Sci. 6, 4176-4187 (2011)

25. J. Schultz, L. Lavielle, C. Martin, J. Chimie. Phys. 84, 231-237 (1987)

26. A. Voelkel, Physicochemical measurements by Inverse Gas Chromatography. In: Poole CF, Gas Chromatography, (Elsevier, Amsterdam, 2012)

27. L. Bacakova, M. Vandrovcova, I. Kopova, I. Jirka, Biomater. Sci. 6, 974 (2018)

28. P. Rani, R. Srivastava, B. Satpati, Cryst. Growth Des. 16, $3323-$ 3333 (2016)

29. G. Mohammadnezhad, O. Akintola, W. Plass, F. Steiniger, M. Westermann, Dalton Trans. 45, 6329 (2016)

30. L. Samain, A. Jaworski, M. Edén, D.M. Ladd, D.-K. Seo, F.J. Garcia-Garcia, U. Häussermann, J. Solid State Chem. 217, 1-8 (2014)

31. Y. Fang, H. Hu, J. Am. Chem. Soc. 128, 10636-10637 (2006)

32. A. Feinle, M.S. Elsaesser, N. Husing, Chem. Soc. Rev. 45, 3377 (2016)

Publisher's Note Springer Nature remains neutral with regard to jurisdictional claims in published maps and institutional affiliations. 